\title{
Performance Analysis of a PV Pump Harvesting Rain Water in the Drought Prone Area of Bangladesh

\author{
Khan Mamun Reza ${ }^{1}$, Subrata Das ${ }^{2}$ and Zahid Hasan Mahmood ${ }^{2}$ \\ ${ }^{I}$ Department of Electronics \& Communication Engineering, Jatiya Kabi Kazi Nazrul Islam University, Trishal Mymensingh, \\ Bangladedsh \\ ${ }^{2}$ Department of Applied Physics, Electronics \& Communication Engineering, University of Dhaka, Dhaka Bangladesh
}

Received on 29.05.2011. Accepted for Publication on 25.09.2011

\begin{abstract}
In this paper the performance of a PV driven water pump, without battery storage, for supplemental irrigation by harvesting rainwater is analyzed. A brushless DC motor is used in this work. The worst day, in terms of rainfall, of the month of July has been chosen for data collection. The variation of the flow rate as a function of the PV array power is found to be linear. Head loss is calculated and found greater at higher flow rate. Lower trend of the subsystem efficiency is observed with the increment of the array power. Considering the module efficiency of the manufacturer, the system efficiency is also calculated and found $3.2 \%$ as the highest. The amount of water lifted is found to be quite satisfactory for supplemental irrigation.
\end{abstract}

\section{Introduction}

In PV water pumping the motor pump setup can be used directly with the array when the motor is DC, or via inverter in the case of AC motor. The common disadvantage of DC motor is the sliding brush contacts and commutator that require a frequent maintenance ${ }^{1}$. For submersible application, the pump is essentially uplifted from the well whenever it requires maintenance and brush replacement. Thus, use of DC motor for irrigation increases the running cost and decreases reliability. Brushless DC motor can be used to overcome this drawback and are normally available for low power applications ${ }^{2,3}$. On the other hand, AC pumping systems using induction motors and inverters offer a reliable alternative ${ }^{4}$. In comparison to DC motors, Induction motors are more reliable and maintenance free. Nevertheless, the main disadvantage with induction motor is the additional inverter cost ${ }^{1}$. In Bangladesh, a substantial potential for the use of solar photovoltaic (PV) energy exists for the purpose of irrigation. But the financial viability of solar PV energy with respect to the other conventional options, i.e. electric or diesel genset (DG), for the pumping of water is the main barrier which slows down its broad adoption $^{5,6,7}$. However, subsidy by the state makes the use of the water pumping by the DG more attractive and thus limiting the emergence of the solar energy even in favorable zones. Under this current scenario, the aim of this work is to analyze the performance of a PV pumping system installed in a drought prone area of the North West site of Bangladesh. This is the first solar pump used for irrigation purpose in Bangladesh. It lifts water from a pond of 100000 $\mathrm{ft}^{3}$ or $2832 \mathrm{~m}^{3}\left(100 * 100 * 10 \mathrm{ft}^{3}\right)$, which can store up to 2832000 liters.

\section{Location of the Pump}

The pump, used for this research, is located at Ginarpur of Gomastapur thana within the district of Chapainawabgonj. Gomastapur is situated at $24^{\circ} 47^{\prime} \mathrm{N}$ of latitude and $88^{\circ} 16^{\prime} \mathrm{E}$ of longitude. The clay surface of the Barind Tract is composed of around $30 \mathrm{~m}$ of fine-grain deposits, however it also contains fine silt and clay with less abundant sand. This clay, sands, gravels and aquifers are the groundwater source in this studied area. Sediments in the top $26 \mathrm{~m}$ of the profile have 5 000-year-old radiocarbon dates. The surface is thought to be the top erosion surface of the Barind clay and underlying sediments are therefore considered much older Barind sediments. The geological properties in the Barind Tract have multiple problems related to water-holding capacity and recurring droughts 8,9

The location is a severe drought prone area. Almost $60 \%$ of the area is under very severe drought and rest of the area is treated as severe drought prone area ${ }^{10}$. During drought period 'Aman' crop suffers from high-yield reduction up to $90 \%{ }^{11}$. As a result most of the farmers do not practice supplemental irrigation as it requires substantial investment. They have to depend on rainfall. If there is not enough rain then the plantation is delayed. Delayed transplanting of aman rice reduces the yield and leaves no land to grow short-duration vegetables, oil seeds (mustard) and pulses (chickpea) before boro rice cultivation. In this situation a low cost way for supplemental irrigation can radically increase the production by more than $50 \%{ }^{10}$.

\section{Specification of the System}

The systems include the following elements:

\section{PV Module}

Here BP 375 solar module without tracking is used. The BP 375 is an advanced $75 \mathrm{~W}$ photovoltaic module that uses cells with antireflective $\mathrm{SiN}$ coating. It is mounted at the roof of a house, north facing with the tilt angle between $24^{\circ}-25^{\circ}$. The rated power of the total set up is 300 watt with 4 modules connected in series. According to manufacturer, the module efficiency is $11 \%$ with the nominal voltage of 12 .

\section{Solar Motor Controller (SMC)}

The SMC comprises a solar maximum power point tracker (MPPT) and brushless DC motor control electronics 
combined in one enclosure. The MPPT adjusts the voltage on the solar array to maximize power generation and increases or reduces this voltage to suit the demands of the motor controller. The motor controller is an electronic commutator replacing the brushes in conventional DC motors. The motor controller senses back-EMF from the motor to determine the rotor position. This information is then fed into a micro computer to calculate the energizing sequence for the motor phases.

\section{Submersible motor-pump unit}

The system consists of a Mono Pump Sun-Sub System containing a high efficiency, brushless, sensor less, permanent magnet, and DC submersible motor designed for coupling to the Mono Pump's Sub rotor. The motor has a sealed, permanent magnet rotor and supported by rolling element bearings with all the drive electronics housed separately on the surface in the SMC. The high operating efficiency of the motor pump and SMC ensures that the maximum amount of water can be pumped over the whole day and during cloudy conditions.

\section{Performance Analysis}

The performance of the system has been analyzed for a worst day situation. The worst day is defined as a cloudy day with no rain. This is the day with a high demand of water but with the lowest irradiation. Data has been taken from 7:38 a.m., when the pump starts, to 5:13 p.m., when it stops. Based on these data Figure 1 is plotted to analyze the performance.

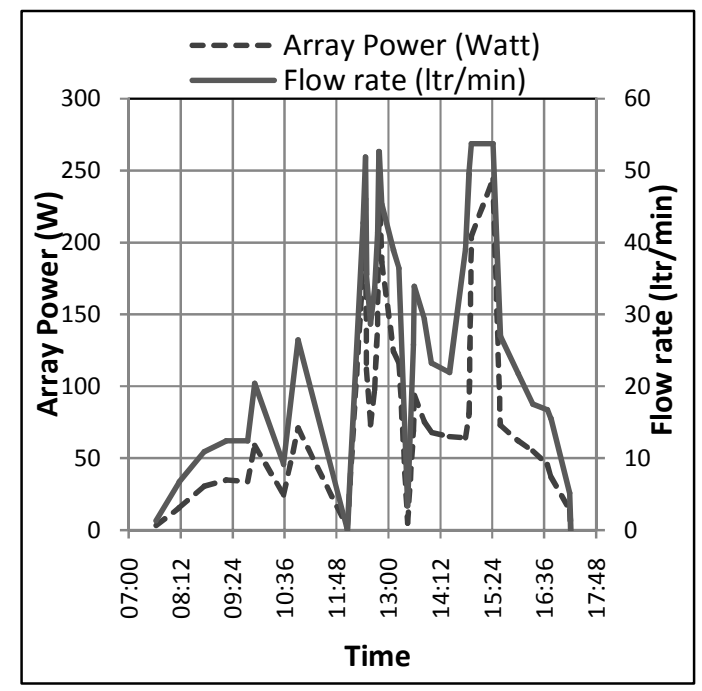

Fig. 1. Variation of array power and flow rate during the test day

In Figure 2 flow rate has been plotted in response to the input PV power. It is found that the flow rate increases almost linearly with the increment of the array power. When the array power reached $3.2 \mathrm{~W}$, the pump started and the flow rate was found to be $1.26 \mathrm{ltr} / \mathrm{min}$. Then the array power gradually increased but suddenly fell to $1.4 \mathrm{~W}$ at $12: 03$ p.m. and the pump stopped. It was raining at that time. The array power reached its highest power of $244 \mathrm{~W}$ at $3: 25 \mathrm{pm}$ when the flow rate reached the highest value of $52.67 \mathrm{ltr} / \mathrm{min}$.

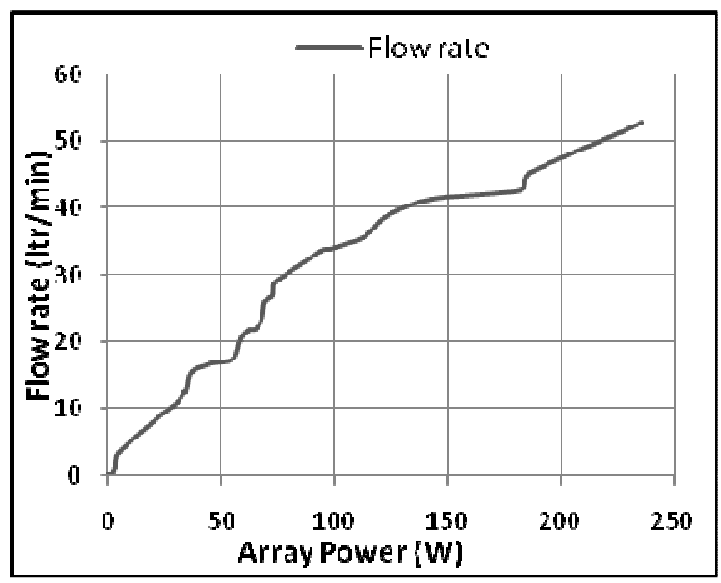

Fig. 2. Measured Flow rate as a function of PV array power

\section{Head loss calculation}

When fluid flows through a pipe, certain resistance is offered to the flowing fluid, which causes loss of energy. These various energy losses in pipes may be classified as:

1. Major/Friction losses

2. Minor losses

\section{Friction loss}

The major loss of energy, as the fluid flows through a pipe, is caused by friction ${ }^{8}$. The head loss due to friction of a pipe is determined by using the Darcy-Weisbach equation.

This loss mainly depends on- flow rate, pipe diameter, pipe length, pipe roughness and the type of fluid. According to Darcy-Weisbach equation,

$$
\mathrm{H}_{\mathrm{f}}=\mathrm{fLv} v^{2} / \mathrm{D}^{2} \mathrm{~g}
$$

Where: $\mathrm{H}_{\mathrm{f}}=$ head loss

$$
\begin{aligned}
& \mathrm{f}=\text { friction factor } \\
& \mathrm{L}=\text { length of pipe } \\
& \mathrm{v}=\text { velocity of fluid through pipe } \\
& \mathrm{D}=\text { Diameter of pipe } \\
& \mathrm{g}=\text { acceleration due to gravity }
\end{aligned}
$$

From Moody diagram the frictional factor is calculated. Here the Reynolds number and the Relative roughness are used to determine the frictional factor. The rougher the pipe the more turbulent is the flow through that pipe. The relative roughness of a pipe is given by,

$$
\frac{e}{D}
$$

Where: $\mathrm{e}=$ absolute roughness 


$$
\mathrm{D}=\text { diameter of pipe }
$$

The Reynolds equation is,

$$
R=\frac{D v}{\zeta}
$$

Where: $\mathrm{R}=$ Reynolds number

$$
\begin{aligned}
& \mathrm{D}=\text { diameter } \\
& v=\text { velocity } \\
& \zeta=\text { kinematic viscosity of fluid }
\end{aligned}
$$

In our calculation Reynolds number is always greater than 4000. So the flow is turbulent.

Now from Moody diagram using the Relative roughness and Reynolds number the frictional factors are found out. Putting this frictional factor (f) in Equation (1) the frictional head loss is calculated. Here absolute roughness is taken as 0.15 (Galvanized iron) and $\zeta=$ kinematic viscosity of fluid as $0.804 \times 10^{-6}$ (taking water temperature $15^{\circ} \mathrm{C}$ at sea level).

\section{Minor loss}

In case of long pipes these losses are usually quite small as compared with the loss of energy due to friction and hence these are termed 'minor losses' which may even be neglected without serious error. However, in short pipes these losses are comparable with friction losses. Minor loss can be due to many reasons. In our set up the Minor loss is due to the loss of energy in bends and at the exit from the pipe to the large tank. Minor loss can be calculated by the equation-

$$
\mathrm{H}_{\mathrm{m}}=\mathrm{K}\left(\mathrm{v}^{2} / 2 \mathrm{~g}\right)
$$

Here, the value of $\mathrm{K}$ is the loss factor, typically provided for various devices and has no unit. $\mathrm{K}$ is computed as -

$$
\mathrm{K}=\mathrm{L}_{\mathrm{e}} / \mathrm{D} * \mathrm{f}_{\mathrm{T}}
$$

Where $\mathrm{L}_{\mathrm{e}}=$ equivalent length (Length of pipe with same resistance as the fitting / valve)

and $f_{T}=$ friction factor. For normal pipe size of 1.5 inch the friction factor $\mathrm{f}_{\mathrm{T}}$ is .021 and for a $90^{\circ}$ elbow the value of $\mathrm{L}_{\mathrm{e}} / \mathrm{D}$ is 50 . So the loss factor $\mathrm{K}=50 * .021=1.05$. The loss of energy due to the exit from a pipe to tank $K=1$ as there are three $90^{\circ}$ elbows.

Thus the total minor loss will be-

$\mathrm{H}_{\mathrm{m}}=(1.05+1.05+1.05+1) \mathrm{v}^{2} / 2 \mathrm{~g}=4.15 * \mathrm{v}^{2} / 2 \mathrm{~g}$.

The velocity of fluid, $\mathrm{v}$ is calculated from the continuity equation by utilizing flow rate.

$$
\mathrm{V}=\mathrm{Q} / \mathrm{A}
$$

Where, $\mathrm{A}=$ area of the pipe and $\mathrm{Q}=$ flow rate.

\section{Total head}

Total head $=$ static head + head loss

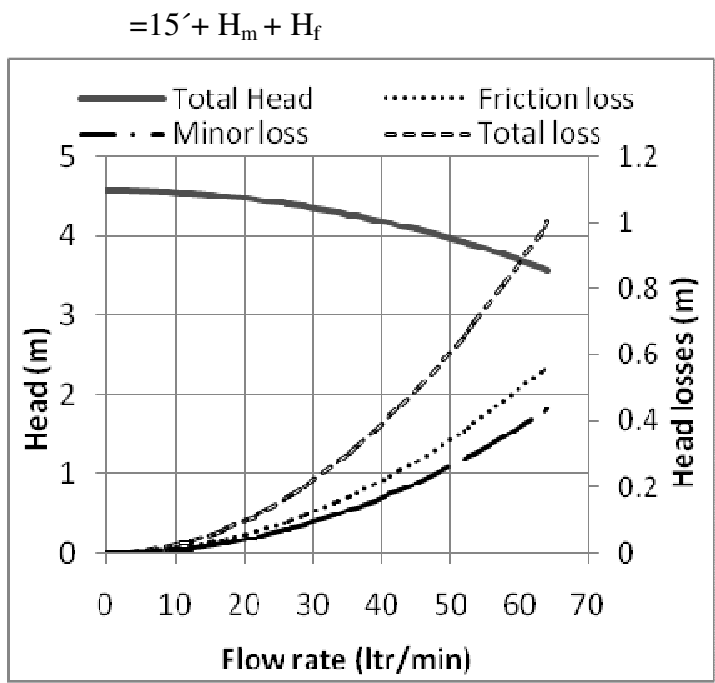

Fig. 3. Measured head-flow characteristics of the pump

\section{Average Efficiencies}

PV array, subsystem and system efficiencies are employed as-

$$
\begin{aligned}
& \eta_{\mathrm{pv}}=\frac{P_{\mathrm{pv}}}{G A}=\frac{I V}{G A} \\
& \eta_{\mathrm{sub}}=\frac{P_{\mathrm{hyd}}}{P_{\mathrm{pv}}}=\frac{\rho g Q H}{P_{\mathrm{pv}}} \\
& \eta_{\mathrm{sys}}=\frac{P_{\mathrm{hyd}}}{G A}=\frac{\rho g Q H}{G A}
\end{aligned}
$$

Average efficiency over any certain period of time are defined by

$$
\begin{aligned}
& \overline{\eta_{\mathrm{pv}}}=\frac{\sum_{i=1}^{n} \eta_{\mathrm{pv}} G}{\sum_{i=1}^{n} G}=\frac{\sum_{i=1}^{n} P_{\mathrm{pv}}}{A \sum_{i=1}^{n} G} \\
& \overline{\eta_{\mathrm{sub}}}=\frac{\sum_{i=1}^{n} \eta_{\mathrm{sub}} P_{\mathrm{pv}}}{\sum_{i=1}^{n} P_{\mathrm{pv}}}=\frac{\sum_{i=1}^{n} P_{\mathrm{hyd}}}{\sum_{i=1}^{n} P_{\mathrm{pv}}} \\
& \overline{\eta_{\mathrm{sys}}}=\frac{\sum_{i=1}^{n} \eta_{\mathrm{sys}} G}{\sum_{i=1}^{n} G}=\frac{\sum_{i=1}^{n} P_{\mathrm{hyd}}}{A \sum_{i=1}^{n} G}
\end{aligned}
$$

Figure 4 shows that the sub system efficiency lies between $16 \%$ to $27 \%$. When the array power is between 70 to $100 \mathrm{~W}$, the sub system efficiency is found greater than $25 \%$ but with the gradual increment of the array power it decreases. As no pyranometer was available in the study area, the actual system efficiency could not be measured. According to the manufacturer the efficiency of this type of solar cell is 
11.8\%. Considering this efficiency the estimated system efficiency is shown in the graph. The highest efficiency is found to be $3.2 \%$

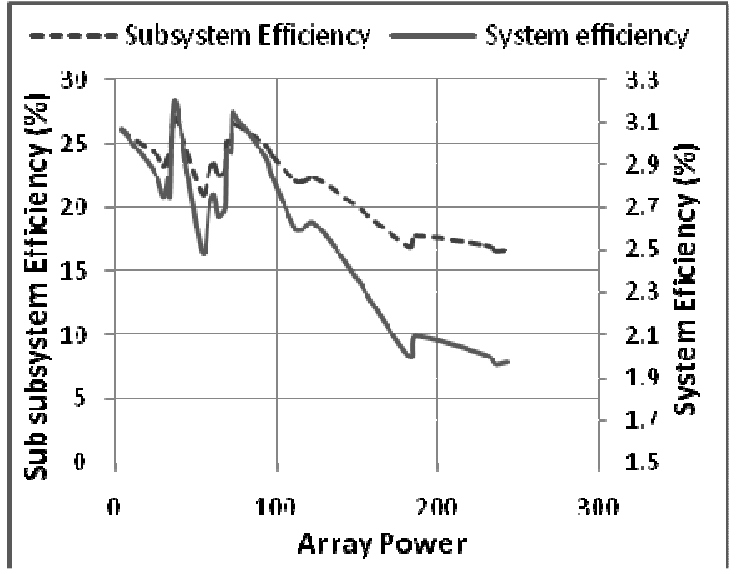

Fig. 4. Variation of the sub system and system efficiency as a function of the array power

\section{Amount of Water Lifted}

Figure 5a shows the array power per hour and Figure $5 \mathrm{~b}$ shows the average amount of water lifted during the test day. Insolation has a major effect on system sizing and its performance. As can be seen in Figure 5a and Figure 5b, water volume quantities are almost negligible at low array power, whereas most water volumes are accumulated at high power intervals. High array power means high insolation. It is therefore concluded that, it is more efficient to design a system that can operate most of the time at or near its rated input power. This may require larger PV array size to provide high power at low insolation levels. However, a careful optimization procedure should be implemented to consider the unutilized PV array power at insolation levels higher than the design insolation point (at which rated pump speed is reached).

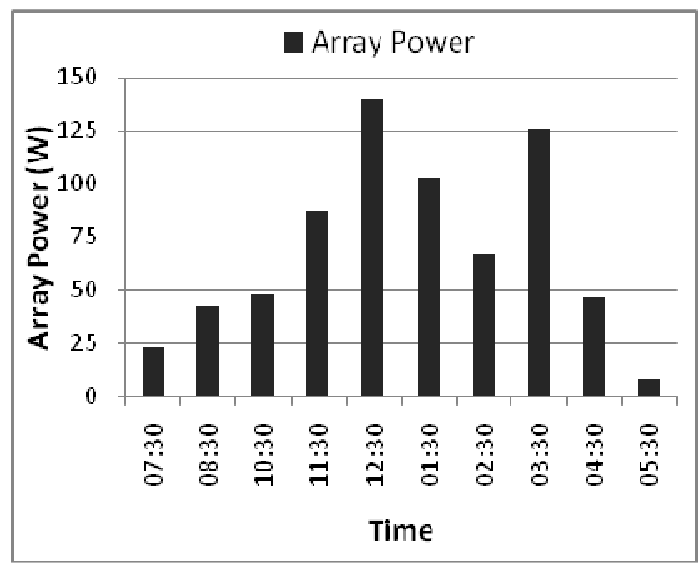

Fig. 5a. Average array power during the test day

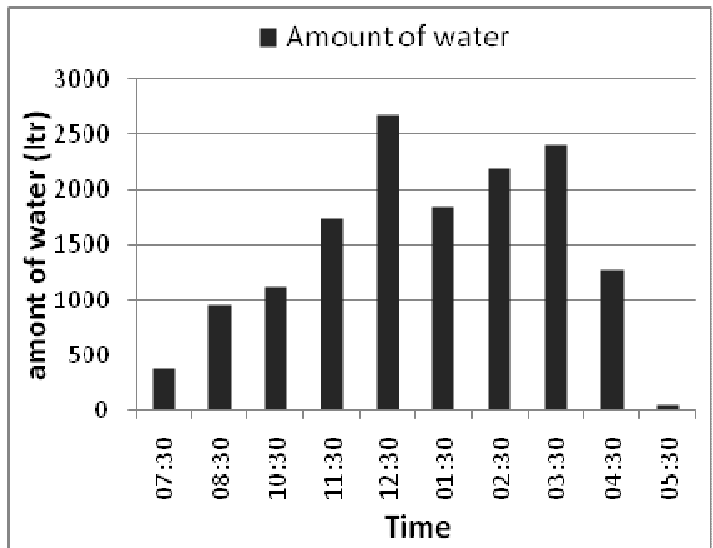

*Note: 7:30 represents the period between 7am to $8 \mathrm{am}$

Fig. 5b. Average water lifted during the test day

Highest amount of water (2673 Liters) was lifted at 12:30 $\mathrm{pm}(12: 00 \mathrm{pm}$ to $1: 00 \mathrm{pm})$ when the array power was also the highest. The total amount of water lifted was 14619 liter (approx.) during the almost 10 hours of operation. It is adequate to irrigate 3 to 4 acres of land for paddy cultivation.

\section{End Use and Related Aspect}

The pump is financed by Caritas Bangladesh (C B). Their main aim is not only to improve the economical condition of the helpless people of this area but also the environment. They realize that lifting of huge amount of water from the ground will have a negative impact on the environment in future. The ground water level is decreasing day by day. That is why they took the step of saving water in the rainy season in ponds for irrigation.

The system is continuously operating for couple of years, have not faced any major technical problem. Users have found this system quite reliable as the mean daily water output is suitable for supplemental irrigation. However, effective end-use management requires an appropriate distribution network and optimized utilization. Since the PV system pumps water from sunrise to sunset, its complete use would not be achieved unless water is stored adequately and distributed effectively.

Since the setup is $100 \%$ environmental friendly it will have a great impact on the environment but the main problem is the cost effectiveness and the awareness of the people about such systems. If the systems are optimized these may be cost effective.

Some steps can be taken to make the system acceptable in this area. This pump is used only for irrigation for only 4 to 5 months. But rest of the time it is useless though the PV module is continuously giving electricity. If this electricity can be utilized then its use will be optimized. It can be used to provide electricity at night by adding a storage battery. In 
the summer when the sun is giving the highest radiation and the PV module is giving the peak electricity then it is totally unused as there is no water in the pond. This electricity may also be used for other applications.

\section{Acknowledgements}

The authors gratefully acknowledge 'Rahimafrooz' and Institute of Renewable Energy Research Centre (RERC), University of Dhaka.

1. Zaki, A., M. Eskander, 1996, Matching of photovoltaic motor- pump systems for maximum efficiency operation. Renewable Energy, 7 (3), 279-288.

2. Betka, A., A. Moussi, 2004, Performance optimization of a photovoltaic induction motor pumping system. Renewable Energy 29, 2167-2181.

3. Barlow, R., B. McNelis, A. Derrick, 1993, Solar pumping: an introduction and update on the technology, performance, costs and economics. World Bank Technical Paper No. 168. Intermediate Technology Publications and The World Bank, Washington, DC, USA. 1993.
4. Yao, Y., P. Baustamente, R. S. Ramshaw, 1994, Improvement of induction motor drive systems supplied by photovoltaic array with frequency control. IEEE Transactions of Energy Conversion 8 (1), 47-52.

5. Purohit P., 2007, Financial evaluation of renewable energy technologies for irrigation water pumping in India, Energy Policy; 35(6):3134-44.

6. Firatoglu Z, B. Yesilata 2004. New approaches on the optimization of directed coupled PV pumping systems. Solar Energy ;77:81-93.

7. Odeh I, YG Yohanis, B. Norton 2006, Economic viability of photovoltaic water pumping systems, Solar Energy;80:850 60.

8. Brammer, H., 2000 Agroecological aspects of agricultural research in Bangladesh. The University press Limited, Dhaka, 371.

9. Year-2006, Book of Agricultural Statistics of Bangladesh.

10. Drought, map-2003, (Ropa Amon).

11. Drought in Bangladesh agriculture and irrigation schedules for major crops. BADC. 